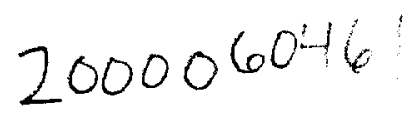

\title{
EFFECTS OF IMPERFECTIONS ON THE BUCKLING RESPONSE OF COMPRESION-LOADED COMPOSITE SHELLS
}

\author{
Mark W. Hilburger" and James H. Starnes, Jr.' \\ NASA Langley Research Center \\ Hampton, VA 23681-2199
}

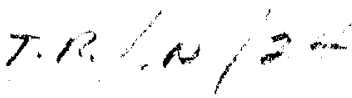

\begin{abstract}
The results of an experimental and numerical study of the effects of imperfections on the buckling response of unstiffened thin-walled composite cylindrical shells are presented. Results that identify the individual and combined effects of traditional initial geometric shell-wall imperfections and non-traditional shell-wall thickness variations, shell-end geometric imperfections and variations in loads applied to the ends of the shells on the shell buckling response are included. In addition, results illustrating the effects of manufacturing flaws in the form of gaps between adjacent pieces of graphite-epoxy tape in some of the laminate plies are presented in detail. The shells have been analyzed with a nonlinear finite-element analysis code that accurately accounts for these effects on the buckling and nonlinear responses of the shells. The numerical results indicate that traditional and nontraditional initial imperfections can cause a significant reduction in the buckling load of a compression-loaded composite shell. Furthermore, the results indicate that the imperfections couple in a nonlinear manner. The numerical results correlate well with the experimental results. The nonlinear analysis results are also compared to the results from a traditional linear bifurcation buckling analysis. The results suggest that the nonlinear analysis procedure can be used for determining accurate, high-fidelity design knockdown factors for shell buckling and collapse. The results can also be used to determine the effects of manufacturing tolerances on the buckling response of composite shells.
\end{abstract}

\section{Introduction}

With the increasing need to produce lighterweight aerospace shell structures, advanced material systems are being used in new designs and improved design and analysis methods appropriate for these advanced material systems are needed. The high

\footnotetext{
- National Research Council Resident Research Associate. Member, AIAA.

+ Senior Engineer, Structures and Materials Competency. Fellow, AIAA

Copyright $@ 2000$ by M.W. Hilburger and J.H. Stames, Jr. Published by the American Institute of Aeronautics and Astronautics, Inc. with permission.
}

strength-to-weight and high stiffness-to-weight ratios of advanced composite materials offer significant weight reduction potential for aerospace structures. In addition, the use of advanced composite materials allows the designer to tailor the stiffness properties of the structure to obtain a structurally efficient design. Traditionally, the approach to designing thin-walled buckling-resistant isotropic shell structures is to predict the buckling load of the shell with a deterministic analysis, and then to reduce this predicted load with an empirical "knockdown" factor (e.g., Ref. 1). The empirical knockdown factor is intended to account for the difference between the predicted buckling load and the actual buckling load of the shell determined from tests. A linear bifurcation buckling analysis is often used for the design-level analysis, and this analysis is usually based on nominal structural dimensions and material properties of an idealized, geometrically perfect shell. The knockdown factor used in the design of buckling-resistant shells is based on the "Lower Bound" design recommendations as reported in Reference 1. This design philosophy can potentially result in overly conservative or unconservative designs of these structures. While it is generally recognized that initial geometric shell-wall imperfections are a major contributor to the discrepancy between predicted buckling loads and experimentally measured shell buckling loads (e.g., Refs. 2-6), the traditional sources of design knockdown factors do not include data or information related to imperfection sensitivity. In addition, the traditional sources of design knockdown factors for predicting shell buckling loads do not include information for composite shell structures. Recent studies (e.g., Ref. 7-12) have shown that traditional initial geometric shell-wall imperfections, and other nontraditional forms of imperfections or variations in geometric and material parameters, loading conditions, and boundary conditions can significantly affect the buckling load of a compressionloaded composite shell structure. The effects of these traditional and nontraditional classes of imperfections on composite shell buckling are generally not well understood by structural engineers and designers. Modern high-fidelity nonlinear analysis procedures offer the opportunity to improve some of the engineering approximations that are used in the design 
of shell structures, and to provide insight into the effects of traditional and nontraditional imperfections on the response of compression-loaded shell structures.

The present paper describes the results of an experimental and numerical study of the effects of traditiona! initial geometric shell-wall imperfections, and variations in other nontraditional geometric and material parameters and loading conditions on the buckling response of unstiffened thin-walled graphiteepoxy laminated cylindrical shells. In addition, results illustrating the effects of manufacturing flaws in the form of gaps between adjacent pieces of graphite-epoxy tape in some of the laminate plies are presented in detail. The results of the study are used to isolate and illustrate the significance of these nontraditional initial imperfections. The nonlinear shell analysis procedure used to predict the buckling and nonlinear response of the shells is described, and the analysis results are compared with the experimental results. The use of this nonlinear shell analysis procedure for determining accurate, high-fidelity design knockdown factors for shell buckling and collapse, and for determining the effects of variations in shell geometric and material parameters on shell buckling is discussed. In addition, the use of this nonlinear analysis procedure for determining manufacturing tolerances of composite shells is discussed. The results from this high-fidelity nonlinear analysis procedure can be used to form the basis for a shell analysis and design approach that addresses some of the critical shell-buckling design criteria and design and manufacturing considerations for contemporary composite shell structures.

\section{Test Specimen, Imperfection Measurements, and Test Apparatus and Tests}

\section{Test Specimen}

The specimen tested in this investigation was fabricated from 0.005-in.-thick AS4/3502 unidirectional graphite-epoxy tape material from Hercules, Inc. The nominal unidirectional lamina properties of a typical 0.005-in.-thick ply are as follows: longitudinal modulus $\mathrm{E}_{1}=20.5 \mathrm{Msi}$, transverse modulus $\mathrm{E}_{2}=1.67 \mathrm{Msi}$, inplane shear modulus $G_{12}=0.87 \mathrm{Msi}$, and major Poisson's ratio $v_{12}=0.30$. The material was laid up on a 15.75-in.-diameter mandrel to form a laminate with a $[\mp 45 / 0 / 90]_{\text {s }}$ quasi-isotropic stacking sequence. The specimen had a nominal length of 16.0 in., a nominal radius of 8.0 in., and a nominal thickness of 0.04 in. Both ends of the specimen were potted in an aluminumfilled epoxy resin to assure that the ends of the specimen did not fail prematurely during the test. The potting material extended approximately 1.0 inch along the length of the specimen at each end resulting in a test section that is approximately $14.0 \mathrm{in}$. long. The ends of the specimen were machined flat and parallel to assure proper load introduction during the tests. The specimen coordinate system used to represent the corresponding geometry is shown in Fig.1. The cylinder length, radius, and thickness are designated as $L, R$, and $t$, respectively.

\section{Imperfection Measurements}

Three-dimensional surveys of the inner and outer shell-wall surfaces of the specimen were made prior to testing to determine the initial geometric shellwall imperfection shape and the shell-wall thickness distribution. Measurements were taken over a uniform grid with increments of 0.125 in. in the axial direction and $0.139 \mathrm{in}$. (approximately $1^{\circ}$ of arc) in the circumferential direction over the exposed surfaces of the specimen. The inner surface measurement was used to determine the initial geometric shell-wall imperfection shape and the difference between the outer and inner surface measurements was used to determine the shell-wall thickness distribution. A contour plot of the nondimensionalized initial geometric shell-wall mid-surface imperfections $\bar{w}_{0}(x, \theta)$ for the specimen is shown in Fig. 2. The measured shell-wall imperfection $w_{0}$ is nondimensionalized by the average measured shell-wall thickness $\mathrm{t}_{\mathrm{avc}}=0.0381$ inches. These results indicate that the initial geometric shellwall imperfection is periodic in the circumferential direction and has slight deviations in the axial direction. The maximum amplitude of the imperfection is 1.535 $t_{\text {ave }}$. A contour plot of the nondimensionalized shellwall thickness variation $\bar{t}_{\circ}(x, \theta)$ for the specimen is shown in Fig. 3. The measured thickness value $t_{o}$ is nondimensionalized by the average measured shell-wall thickness $t_{\text {ave }}$. These results indicate that the shell-wall thickness, and hence the laminate stiffnesses, varies significantly over a short distance. The thickness varies from 0.928 to 1.321 times $t_{\text {uve }}$. Most of the thickness variation is attributed to local variations in the resin content of the laminate. However, the darker angular pattern in the thickness distribution is caused by gaps between adjacent pieces of graphite-epoxy tape in some of the laminate plies that were generated during the layup and curing process. Such a region is referred to herein as a lamina ply-gap or ply-gap. In such a locally thin region, the shell wall is a 7 -ply-thick laminate rather than the nominal 8-ply-thick laminate. In the case where one ply-gap intersects another ply-gap the shell wall is a 6-ply-thick laminate. In addition, these locally thin regions of the shell wall have, associated with them, a significant mid-surface eccentricity. Typically, a circumferential ply-gap constitutes a gap between two adjacent $90^{\circ}$ pieces of tape in the ply, a $45^{\circ}$ or helical ply-gap constitutes a gap between two adjacent $45^{\circ}$ pieces of tape, and an axial ply-gap 
constitutes a gap between two adjacent $0^{\prime \prime}$ pieces of tape. Magnified cross-sectional views of ply-gaps in a $45^{\circ}$ outer ply of the specimen laminate and a $90^{\prime \prime}$ midsurface ply are shown in Figs. $4 a$ and $4 b$, respectively. The widths of the ply-gaps shown in Figs. $4 \mathrm{a}$ and $4 \mathrm{~b}$ are on the order of $0.02 \mathrm{in}$. or approximately half the wall thickness, and the ply-gap depth is between 0.001 -in. and 0.005 -in. (the nominal lamina ply thickness is 0.005 -in.). However, other observed ply-gaps in the specimen have widths as large as $0.1 \mathrm{in}$. The lighter angular patterns in the thickness contour plot are caused by pinching of the outermost lamina plies of the laminate which forms an outer shell-wall surface ridge. A magnified cross-sectional view of such a region is shown in Fig. 4c.

Measurements of the top and bottom loading surfaces of the specimen were made every degree around the circumference of the specimen to determine the variation in the shell-end or loading-surface geometry. Typical top and bottom shell-end or loadingsurface geometry variations for the specimen are denoted by $\delta_{\text {top }}(\theta)$ and $\delta_{\text {bor }}(\theta)$, respectively, and are shown in Fig. 5. The maximum amplitude of this shellend or loading-surface variation is approximately 0.0015 inches, which is approximately $4 \%$ of $t_{\text {ave }}$ and $0.01 \%$ of the specimen length.

\section{Test Apparatus and Tests}

The specimen was instrumented with electrical resistance strain gages and direct-current differential transducers (DCDT's) were used to measure displacements. Three non-collinear DCDT's were positioned in three corners of the upper loading platen and used to measure the end-shortening displacement $\Delta$ and the rotations $\phi_{y}$ and $\phi_{z}$ of the loading platen as illustrated in Fig. 1. A moiré interferometry procedure was used to observe the shell-wall prebuckling, buckling and postbuckling out-of-plane (perpendicular to the shells outer surface) deformation patterns. All data were recorded with a data acquisition system, and the moire patterns corresponding to the response of the specimen was recorded photographically and on videotape.

The specimen was loaded in compression with a 300 Kip hydraulic universal-testing machine by applying an end-shortening displacement to the shell ends or loading surfaces of the specimen. To control the load introduction into the specimen, the upper loading platen was aligned with the loading surface of the specimen before the test by adjusting leveling-bolts in the corners of the upper loading platen until strains measured by selected strain gages indicated a uniform axial strain distribution in the shell wall. The specimen was loaded until general instability of the shell occurred.

\section{Finite-Element Models and Analyses}

\section{Nonlinear Analysis Procedure}

The shells considered in this study were analyzed with the STAGS (STructural Analysis of General Shells) nonlinear shell analysis code. ${ }^{13}$ STAGS is a finite-element code designed for the static and dynamic analysis of general shells, and includes the effects of geometric and material nonlinearities in the analysis. The code uses both the modified and full Newton methods for its nonlinear solution algorithms, and accounts for large rotations in a shell by using a corotational algorithm at the element level. The Riks pseudo arc-length path-following method ${ }^{14}$ is used to continue a solution past the limit points of a nonlinear response. With this strategy, the incrementally applied loading parameter is replaced by an arc-length along the solution path, which is then used as the independent loading parameter. The arc-length increments are automatically adjusted by the program as a function of the solution behavior. The transient analysis option in STAGS uses proportional structural damping and an implicit numerical time-integration method developed by Park. ${ }^{15}$ Additional information on the transient analysis can be found in Ref. 16.

The prebuckling, buckling and postbuckling responses of the shells were determined using the following analysis procedure. The prebuckling responses were determined using the geometrically nonlinear quasi-static analysis capability in STAGS. The Riks pseudo arc-length path-following method, described previously, was used to compute the initial shell response until just before buckling. The unstable buckling response of the shell was predicted using the nonlinear transient analysis option of the code. The transient analysis was initiated from an unstable equilibrium state close to the limit point by incrementing the end displacement by a small amount. An initial time step of $1.0 \mathrm{E}-8$ seconds was used in the analysis and is automatically adjusted by the program as a function of the solution behavior. The transient analysis was continued until the kinetic energy in the shell was dissipated to a negligible level, which indicates that the transient response has attenuated. Once the transient analysis had attenuated to a nearsteady-state solution, the load relaxation option of the code was used to establish a static equilibrium state. A conventional linear bifurcation buckling analysis result was also determined with STAGS for comparison with the nonlinear response results.

\section{Finite-Element Models}

A typical finite-element model of a specimen is illustrated in Fig. 1. The standard 410 quadrilateral from the STAGS element library was used in the 
models. The elements of the finite-element mesh are approximately 0.2 -in. by 0.2 -in. square. Each element possesses four integration points, which are distributed in such a way as to provide a modeling resolution of approximately 0.1 -in. by 0.1 -in square. This integration point spacing is on the order of the measurement point spacing used when measuring the initial geometric imperfections of the specimen. This highly refined mesh is able to model rapidly varying geometric and material parameters such as nonuniform shell-wall thickness and lamina stiffness properties.

Idealizations of the end conditions with the potting material were used in the finite-element models. To simulate the constraints provided by the potting material, the circumferential and out-of-plane stiffness contributions of the potting material were calculated and applied to the edge regions of the shell indicated in Fig. 1.

Geometrically perfect and imperfect shells were analyzed in the present investigation. Nominal shell geometry, laminate thickness and lamina mechanical properties were used for the finite-element model for the geometrically perfect shell. The geometrically perfect finite-element model was modified to include the effects of the measured shell imperfections to simulate more closely the response of the specimen. These modeling modifications include the measured initial geometric shell-wall mid-surface imperfections, shell-wall thickness variations, thickness-adjusted lamina properties, shell-end geometric imperfections, and nonuniform end loads. The initial geometric shell-wall mid-surface imperfection $w_{0}(x, \theta)$ is included in the finite-element models by introducing an initial out-of-plane perturbation to each node of the mesh by using a userwritten subroutine. The user-written subroutine uses a linear interpolation algorithm that calculates the value of the imperfection at each nodal coordinate which is based on the measured shell-wall data. The shell-wall thickness, $t$, and lamina material properties, $E_{1}, E_{2}$, $G_{12}$, and $v_{12}$, are adjusted at each integration point of each element in the finite-element model.

Two imperfect shell-wall laminate models are considered in the present study based on two different interpretations of the measured thickness data. The first model of the shell-wall laminate assumes that any variation in the shell-wall laminate thickness is due to a variation in the resin volume only. The second model identifies local thin regions in the shell-wall as lamina ply-gaps and adjusts the laminate stiffness properties by reducing the thickness of the appropriate lamina ply in the shell-wall laminate model. A typical finite-element laminate model including a lamina ply-gap detail is illustrated in Fig. 6. The nominal shell-wall laminate is 8 -plies thick with the inner ply defined as ply 1 and the outer ply defined as ply 8 . The inner shell-wall surface was placed against the fabrication tool and is considered smooth and continuous. Any thickness variation in the shell wall is applied to the outer surface of the laminate. The finite-element nodes and integration points are represented by filled circle and square symbols, respectively. The lamina ply-gap width and ply-gap depth are denoted by gw and gd , respectively. The shell-wall mid-surface eccentricity is denoted by ecz and is calculated relative to the average shell-wall mid-surface; that is, $\operatorname{ecz}(x, \theta)=$ $0.5\left(t_{\text {ave }}-t_{0}(x, \theta)\right)$. The lamina properties are adjusted by using the rule of mixtures. In the rule-of-mixtures calculations, it is assumed that any variation in the lamina ply thickness from the nominal thickness is due to a variation in resin volume only, and that the fiber volume remains constant for each ply. Nonuniform end loading of the specimen is attributed to initial specimen-end or loading-surface imperfections and to upper loading platen rotations that are measured during the experiment. First, the measured upper and lower specimen-end or loading-surface imperfections $\delta_{\text {top }}(\theta)$ and $\delta_{\text {bot }}(\theta)$, respectively, were included in the finiteelement model by introducing an initial in-plane axial perturbation to the nodes at the loaded ends of the shell. Then, the compression load was applied to the cylinder in two parts. The nonuniform specimen-end imperfections, $-\delta_{\text {top }}(\theta)$ and $-\delta_{\text {bor }}(\theta)$, were applied to the upper and lower ends of the shell, respectively, as displacements at the beginning of the analysis to simulate a full contact condition between the shell ends or loading surfaces and the loading platens. Then, the experimentally measured end-shortening displacement $\Delta$ and upper loading-platen rotations $\phi_{y}$ and $\phi_{z}$ were applied to the upper shell end or loading surface while holding the lower loading surface fixed as illustrated in Fig. 1; that is, $u(0, \theta)=\Delta+R \cos \phi_{y} \cos \theta+R \cos \phi_{z} \sin$ $\theta-\delta_{\text {top }}(\theta)$ and $u(L, \theta)=-\delta_{\text {bor }}(\theta)$. A typical finiteelement model contained approximately 100,000 degrees of freedom and a typical nonlinear analysis required 3 CPU hours on an engineering workstation.

\section{Results and Discussion}

Numerically predicted and experimentally measured results for the compression-loaded graphiteepoxy cylindrical shell considered in this study are presented in this section. The predicted results were obtained from finite-element models that include initial geometric shell-wall mid-surface imperfections, shellwall thickness variations and thickness-adjusted lamina properties, and nonuniform loading effects. These results are presented to illustrate the overall behavior of compression-loaded graphite-epoxy shells and the effects of imperfections on their response. First, results illustrating a typical nonlinear response of a 
compression-loaded geometrically perfect quasiisotropic cylindrical shell are presented. Then results indicating the effects of manufacturing flaws in the form of lamina ply-gaps on the compression response are presented. Next, results illustrating the effects of initial shell geometric and loading imperfections on the buckling response are presented. Finally, a comparison between selected numerically predicted results and experimentally measured results is presented. The results include predicted and measured load-endshortening response curves, predicted prebuckling, buckling and postbuckling deformation response patterns.

\section{Nonlinear Response of a Geometrically Perfect Cylindrical Shell}

Results from a nonlinear analysis of the cylindrical shell considered in this study are presented in Fig. 7. The load-end-shortening curve indicates a linear prebuckling response. The general instability occurs at an axial load level of $45.9 \mathrm{Kips}$, marked by the letter A in Fig. 7a. A transient collapse response occurs after point $A$ and the load-time history for the collapse response is given in Fig. $7 \mathrm{~b}$. The general instability in the shell is caused by a nonlinear coupling between destabilizing compressive axial and circumferential stresses and the out-of-plane deformations in the bending boundary layer near the ends of the shell. The results indicate an initial spike in the axial load at the onset of buckling. This spike in load is due to the initial impulse load applied to the shell at the beginning of the transient analysis. The axial load decays to a steady state value of $46.1 \mathrm{Kips}$ quickly and remains at that level until approximately 0.0046 seconds into the transient response when a sudden reduction in axial load occurs and the global collapse of the shell begins. The load level continues to decrease until approximately 0.01 seconds into the transient response when the axial load has come to a steady state value of 14.32 Kips. The kinetic energy in the shell dissipates over time and the shell reaches stable postbuckling equilibrium after approximately 0.02 seconds have ellapsed. The transient deformation responses for selected time steps during the transient buckling response indicated by the letters $A$ through $F$ in Fig. $7 \mathrm{~b}$ are presented in Figs. 7c through $7 \mathrm{~h}$, respectively. At the onset of buckling, the shell-wall out-of-plane deformations change in a very short period of time from the uniform axisymmetric prebuckling deformation pattern indicated by Deformation Pattern A in Fig. $7 \mathrm{c}$ to a transient unstable deformation pattern indicated by Deformation Pattern B in Fig 7d. The results indicated by Deformation Pattern $B$ show that the initial buckling deformations are characterized by localized ellipse-like or diamond-shaped buckles in the bending boundary layer near the ends of the shell. As the buckling process continues, there is a significant reduction in the axial load, and the local buckles in the deformation pattern increase in number and are redistributed around the shell as indicated by Deformation Pattern $\mathrm{C}$ in Fig 7e. As the buckling process continues, the deformation pattern in the shellwall continues to evolve as indicated by Deformation Patterns $D$ and $E$ in Figs. $7 f$ and $7 g$, respectively. In particular, Deformation Pattern $E$ indicates that the buckles in the shell wall are beginning to coalesce into larger buckles. After approximately 0.02 seconds have elapsed, the kinetic energy of the shell has dissipated to a negligible level, and the shell has deformed into a stable postbuckling mode-shape that consists of 16 halfwaves around the circumference and two half-waves along the length, as indicated by Deformation Pattern $F$ in Fig. 7h.

\section{Effects of Manufacturing Defects}

A parametric study of the effects of manufacturing defects on the compression response of the quasi-isotropic shell was conducted. The manufacturing defects considered are in the form of lamina ply-gaps. Nominal shell dimensions and material properties were used in the finite-element models. Ply-gaps in each of the lamina plies were studied, and included circumferential ply-gaps located at the shell mid-length, $+45^{\circ}$ and $-45^{\circ}$ helical ply gaps, and axial ply-gaps. Ply-gap widths (gw) of 0.1 and 0.2 in. and ply-gap depths (gd) of 0.0025 and 0.005 in. were considered. The appropriate lamina ply thickness was reduced in the region of the ply-gap, in some cases resulting in a locally unsymmetric laminate, and the shell-wall mid-surface eccentricity was included in the finite-element model as illustrated in Fig. 6.

Results indicating the effects of $-45^{\circ},+45^{\circ}, 0^{\circ}$ and $90^{\circ}$ lamina ply-gaps on the buckling load of a quasi-isotropic cylindrical shell are presented in Fig. 8a through $8 \mathrm{~d}$. The open square and open circle symbols in the figure represent the buckling loads for shells with an outer-layer ply-gap (i.e., layer $5,6,7$, or 8) with gap depths of $0.0025 \mathrm{in}$. and $0.005 \mathrm{in}$., respectively. The filled square and filled circle symbols in the figure represent the buckling loads for shells with an innerlayer ply-gap (i.e., layer 1, 2, 3, or 4) with gap depths of 0.0025 in. and 0.005 in., respectively. In general, the results indicate that, for a fixed ply-gap depth, the buckling load decreases as the ply-gap width increases. Similarly, for a fixed ply-gap width, the buckling load decreases as the ply-gap depth increases. In addition, the results indicate that for a fixed ply-gap orientation, the location of the ply-gap within the laminate can have a significant effect on the buckling response of the shell as shown for cylinders with $-45^{\circ},+45^{\circ}$ ply-gap in Fig. 8 a and $8 \mathrm{~b}$, respectively. More specifically, these results suggest that the variation in the bending stiffness and 
eccentricity in the region of the ply-gap can have a significant effect on the buckling load of the shell. The results also indicate that the axially aligned ply-gaps in a shell cause less than $1 \%$ reduction in the buckling load of the shell as shown in Fig. 8c. In contrast, cylinders with $-45^{\circ},+45^{\prime \prime}$ and $90^{\prime \prime}$ ply-gaps considered in this study can exhibit $5.9 \%, 3.3 \%$ and $10.5 \%$ reductions in the buckling load of a shell, as indicated in Figs. 8a, 8b, and 8d, respectively.

Results illustrating the transient deformation response during the collapse of a cylinder with a $-45^{\circ}$ helical ply-gap and $\mathrm{gw}=0.2 \mathrm{in}$. and $\mathrm{gd}=0.005 \mathrm{in}$. are presented in Fig. 9. At the onset of buckling (Time = 0.0 seconds) the deformation pattern in the shell-wall is characterized by a long inward buckle aligned with the helical ply-gap and ellipse-shaped buckles at the intersection of the ply-gap and the bending boundary layer near the ends of the shell as indicated by the deformation pattern shown in Fig. 9a. The ellipseshaped buckles in the bending boundary layer couple with localized destabilizing compressive axial and circumferential stresses in the bending boundary layer near the ends of the shell and excite the initial buckling mode-shape in the shell (see Deformation Pattern B in Fig. $7 \mathrm{~d}$ for the initial buckling mode-shape of the geometrically perfect shell) and cause the shell to buckle at a lower applied load. The shell deformation pattern changes in a short period of time from the prebuckling deformation pattern to the transient unstable pattern indicated by the deformation pattern shown in Fig. 9b. The results indicate that the deformations are characterized by a localized group of ellipse-shaped or diamond-shaped buckles near the helical ply-gap in the shell. As the buckling process continues, there is a significant reduction in the axial load supported by the shell, and the local buckles in the deformation pattern increase in number and are redistributed around the circumference of the shell as indicated by the deformation pattern shown in Fig. 10c. After approximately 0.029 seconds have ellapsed, the kinetic energy in the shell has dissipated to a negligible level and the shell has deformed into a stable postbuckling mode-shape that consists of 16 half-waves around the circumference and two half-waves along the length, as indicated by the deformation pattern in Fig. $9 d$.

Results illustrating the transient deformation response during the collapse of a shell with an axially aligned ply-gap and $\mathrm{gw}=0.2 \mathrm{in}$. and $\mathrm{gd}=0.005 \mathrm{in}$. are presented in Fig. 10. The shell wall deformations at the onset of buckling indicated by the deformation patterns shown in Fig. 10a are characterized by an axisymmetric deformation response similar to that of a geometrically perfect shell (see Deformation Pattern A in Fig. 7c). The prebuckling response appears to be unaffected by the addition of the ply-gap in the shell- wall as indicated by the axisymmetric deformation response and this result is consistant with the fact that there is less than $1 \%$ reduction in the buckling load due to the ply-gap. The general instability in the shell is caused by a nonlinear coupling between destabilizing compressive axial and circumferential stresses and the out-of-plane deformations in the bending boundary layer near the ends of the shell. As buckling proceeds, the shell deforms into a transient unstable bucklingmode indicated by the deformation patterns shown in Fig. 10b. This deformation pattern is characterized by localized groups of ellipse-shaped buckles near the ends of the shell and centered around the axially aligned plygap. As the buckling process continues, there is a significant reduction in the axial load and the local buckles in the deformation pattern increase in number and are redistributed around the circumference of the shell as shown by the deformation pattern shown in Fig. 10c. After approximately 0.0271 seconds have ellapsed, the shell has deformed into a stable postbuckling mode-shape that consists of 16 half-waves around the circumference of the shell, two half-waves along the length, and two additional smaller diamondshaped buckles aligned with the axial ply-gap near the ends of the shell, as indicated by the deformation pattern shown in Fig. 10d.

Results illustrating the transient deformation response during the collapse of a shell with a circumferentially aligned ply-gap and $\mathrm{gw}=0.2$ in and $\mathrm{gd}=0.005 \mathrm{in}$. are presented in Fig. 11 . At the onset of buckling, the shell deformations are characterized by an axisymmetric deformation shape as indicated by the deformation pattern shown in Fig. $11 \mathrm{a}$. The general instability in the shell is caused by a nonlinear coupling between localized destabilizing compressive axial and circumferential stresses and the out-of-plane deformations in the region near the ply-gap. The axisymmetric deformation response is quickly followed by an unstable transient buckling mode indicated by the deformation pattern shown in Fig. $11 \mathrm{~b}$. The deformation pattern is characterized by 12 ellipseshaped buckles aligned with the circumferential ply-gap at the shell mid-length. This buckling mode is similar to the mode observed in the bending boundary layer of the geometrically perfect shell during the initial stages of buckling (see Deformation Pattern B in Fig. 7d). This result suggests that the axisymmetric deformation response in the shell with a circumferential ply-gap is exciting a similar initial unstable transient buckling mode in the shell at lower applied load levels. As buckling continues, there is a significant reduction in the axial load and the local buckles in the deformation pattern increase in number and are redistributed along the length of the shell as shown by the deformation pattern shown in Fig. 11c. After approximately 0.0299 seconds have ellapsed, the shell has deformed into a 
stable postbuckling mode-shape that consists of 16 halfwaves around the circumference of the shell and two half-waves along the length, as indicated by the deformation pattern shown in Fig. 11d.

Results illustrating the effects of $-45^{\circ}$ and $90^{\circ}$ ply-gaps on the buckling response of cylindrical shells suggest that the prebuckling deformation response can cause the buckling of the shell to occur at lower applied loads due to an interaction with or excitation of the initial buckling deformation pattern in the shell. The geometrically perfect cylindrical shell in the present study exhibits an initial buckling deformation pattern that is characterized by 12 circumferentially aligned ellipse-shaped or diamond-shaped buckles in the bending boundary layer near the ends of the shell (see Fig. 7d). The corresponding circumferential half-wave length of the buckles is approximately 2.1 in. and the buckles exhibit an axial half-wave length of approximately $2.0 \mathrm{in}$. in the bending boundary layer of the shell; that is, they extend from $x=1.0$ in. to 3.0 in. and $x=13.0$ in. to 15.0 in. along the length of the shell. The previous results indicated a strong interaction between the prebuckling shell-wall deformations near the lamina ply-gaps and the initial unstable buckling deformations in the shell. These results suggest that there might exist a critical gap length, $\mathrm{gl}_{\mathrm{cr}}$, required to produce a prebuckling deformation response that can interact with or excite the initial unstable buckling mode in the shell. To determine such a critical gap length, a numerical parametric study was conducted for cylindrical shells with $-45^{\circ}$ helical ply-gaps and $90^{\circ}$ circumferential ply-gaps. Results illustrating the effects of $-45^{\circ}$ helical ply-gaps and $90^{\circ}$ circumferential plygaps of varying lengths are presented in Figs. $12 \mathrm{a}$ and $12 \mathrm{~b}$, respectively. The open square and open circle symbols in the figure represent the buckling loads for shells with a ply-gap width of 0.1 in. and with gap depths of 0.0025 in. and 0.005 in., respectively. The filled square and filled circle symbols in the figure represent the buckling loads for shells with a ply-gap width of $0.2 \mathrm{in}$. and with gap depths of $0.0025 \mathrm{in}$. and 0.005 in., respectively. The results indicate that, in both cases, a significant reduction in the buckling load of the shell can occur when the lengths of the ply-gaps reach a critical length. The $-45^{\circ}$ ply-gap reaches a critical length between $\mathrm{gl} / \mathrm{L}=0.0625$ and $\mathrm{gl} / \mathrm{L}=0.1875$ which coincides with the location of the buckles that exist in the bending boundary layer in the initial unstable buckling mode shape (see Fig. 7d) as indicated in Fig. 12a. The $90^{\circ}$ ply-gaps reach a critical length $\mathrm{gl} / 2 \pi \mathrm{R}=$ 0.0417 which corresponds to the half-wave length of the initial unstable buckling mode shape (see Fig. 7d) as indicated in Fig $12 \mathrm{~b}$.
Effects of Initial Imperfections on the Buckling Response

Results from a numerical parametric study isolating and illustrating the effects of initial imperfections on the buckling response of the shell are presented in this section. The imperfections studied include traditional initial geometric shell-wall midsurface imperfections and other nontraditional shellwall imperfections, and nonuniform loading effects. The nontraditional shell-wall imperfections include the effects of measured shell-wall thickness variations and thickness adjusted lamina mechanical properties. The nonuniform loading conditions include the effects of initial shell-end imperfections. Imperfection scaling factors were introduced into the models to allow for independent variations in the imperfection amplitudes during the study. Imperfection scale factors for the shell-wall mid-surface imperfection, shell-end or loading-surface imperfection, and shell-wall thickness imperfection are denoted by $\tilde{w}, \tilde{\delta}$, and $\tilde{t}$, respectively. Imperfection scale factor values equal to $0.0,0.5$, and 1.0 were considered in this study. The lamina ply-gap in the present model were assumed to have a gap width of 0.1 in. and a gap depth of 0.005 in. which is representative of the what was found in the actual specimen: The results indicate that the buckling load of the shell can be affected by each of these types of imperfections.

Results illustrating the effects of shell-wall mid-surface imperfection and shell-end or loadingsurface imperfection for a shell with uniform thickness $(\tilde{t}=0.0)$ and nonuniform thickness and laminate mechanical properties $(\bar{t}=1.0)$ are shown in Figs. 13a and $13 \mathrm{~b}$, respectively. The open square, open circle, and open triangle symbols in the figure represent the buckling loads for a shell with shell-end or loadingsurface imperfection magnitudes of $0.0,0.5$, and 1.0 , respectively. The results show that the imperfections couple in a nonlinear manner. More specifically, the results indicate that the buckling load decreases as the magnitude of the mid-surface imperfection increases. In addition, the results indicate that for small-magnitude mid-surface imperfections, the shell-end or loadingsurface imperfection can cause a significant reduction in the buckling load of the shell. However, the effects of shell-end or loading-surface imperfection on the buckling load become less significant as the midsurface imperfection increases in magnitude. Results for $\tilde{t}=0.5$ were obtained and exhibit similar trends and buckling load values 1 to $2 \%$ lower than those presented in Fig. 13a for $\bar{t}=0.0$. Results illustrating the effects of shell-wall mid-surface imperfection, shell-end or loading-surface imperfection for a shell with nonuniform thickness and lamina ply-gaps $(\overline{\mathrm{t}}=$ 1.0) are presented in Fig. 13b. The results indicate a 
reduction in the buckling load of the shell due to the effects of the nonunitorm thickness and lamina plygaps for all values of the mid-surface impertection amplitude when compared to the results in Fig. 14a. In addition, the results indicate that the effects of the shellend or loading-surface impertection on the buckling load become less significant as the mid-surface imperfection amplitude increases.

A similar parametric study was conducted to identify the effects of the local laminate stiffness properties in the region of the lamina ply-gaps on the buckling load of the compression-load shell. In this study, it was assumed that the shell-wall thickness variation was due to variations in the laminate resin volume only, thus any significant stiffness reduction in the region of the ply-gap was omitted from the model. The results from these models showed less than $1 \%$ difference in the predicted buckling load values, on average, when compared to the buckling loads predicted from the models that included the effects of lamina ply-gaps. These results are interesting results since earlier results indicated that local bending stiffness variations in the region of a single ply-gap could have a significant effect on the buckling load of a geometrically perfect shell (see Figs. 8a-8d). In contrast, the present results suggest that the local stiffness reduction has little influence on the buckling load of the shell and that the local shell-wall eccentricity is the important feature of the thickness variation in the shell-wall.

\section{Predicted and Measured Response Comparisons}

Selected results from nonlinear analyses and a traditional bifurcation buckling analysis of a cylindrical shell are compared to the experimentally measured results in this section. The traditional bifurcation buckling analysis was preformed for a geometrically perfect shell with nominal geometric and material properties. The nonlinear analysis results are from a geometrically perfect shell model and a model that includes the effects of the measured initial imperfections and experimentally measured loadingplaten displacements and rotations. Experimentally measured loading-platens rotations $\phi_{y}$ and $\phi_{z}$ of $1.57 \mathrm{E}-4$ and $0.92 \mathrm{E}-4$ radians were included in the model.

Numerically predicted and experimentally measured load-end-shortening response curves are shown in Fig. 14. The predicted buckling loads are indicated by the filled symbols and the measured buckling load is indicated by an open square symbol in the figure. The traditional linear bifurcation buckling load is marked by the horizontal dashed line in the figure and represents a buckling load of 48.44 Kips. The measured results indicate a buckling load of 34.18 Kips and an initial postbuckling residual load of 11.49
Kips. The predicted results for a geometrically perfect cylinder indicate a buckling load of $45.9 \mathrm{Kips}$ and an initial postbuckling residual load level of 14.32 Kips. The shell that includes the effects of measured initial imperfections and experimentally measured loading conditions exhibits a buckling load of $39.35 \mathrm{Kips}$ and an initial postbuckling residual load of $14.3 \mathrm{Kips}$. The predicted buckling load is $18.8 \%$ lower than the corresponding bifurcation buckling load, and $14.27 \%$ lower than the predicted buckling load of the geometrically perfect shell from a nonlinear analysis.

While these results indicate a significant improvement in the buckling load predictions of the compression-loaded composite cylinder, the experimentally measured buckling load of the specimen is $13.1 \%$ lower than the buckling load predicted by the nonlinear analysis of the imperfect shell and the initail postbuckling residual load is $19.7 \%$ lower. In addition, results indicate that the predicted prebuckling stiffness of the imperfect shell is $1060.18 \mathrm{Kips} / \mathrm{in}$. and the measured prebuckling stiffness is $1035.76 \mathrm{Kips} / \mathrm{in}$. representing a $2.4 \%$ difference. To improve the correlation between the predicted and measured prebuckling stiffness, the nominal lamina fiber volume fraction used in the finite-element model of the imperfect cylindrical shell was reduced $3.2 \%$ from 0.62 to 0.60 . This change resulted in a predicted prebuckling stiffness of $1028.93 \mathrm{Kips} / \mathrm{in}$. as compared to the measured prebuckling stiffness $1035.76 \mathrm{Kips} / \mathrm{in}$. which is $0.66 \%$ lower than the measured stiffness, and represents a $2.9 \%$ reduction in the predicted prebuckling stiffness from the imperfect shell model with a lamina fiber volume fraction of 0.62 . In addition, the predicted buckling load was reduced $3.6 \%$ from $39.35 \mathrm{Kips}$ to $37.95 \mathrm{Kips}$ and the initial postbuckling residual load was reduced $1.5 \%$ from 14.3 Kips to 14.09 Kips. These results indicate that variations in lamina fiber volume fraction can have an affect on the prebuckling, buckling and postbuckling response of the shell.

\section{Concluding Remarks}

The results of an experimental and analytical study of the effects of imperfections on the buckling response of thin unstiffened graphite-epoxy cylindrical shells have been presented. The results identify the effects of traditional initial geometric shell-wall imperfections on the nonlinear response and buckling loads of these shells that are commonly discussed in the literature on shell buckling. Other results are presented that identify the effects of several relatively unknown and nontraditional imperfections such as shell-end geometric imperfections, shell-wall thickness variations, and variations in loads applied to the ends of the shells on the shell buckling and nonlinear responses. 
A high-fidelity nonlinear shell analysis procedure has been used to predict the response of the shells, and this analysis procedure accurately accounts for the effects of these traditional and nontraditional imperfections on the buckling and nonlinear responses of the shells. The analysis results correlate well with the experimental results indicating that it is possible to predict the complex nonlinear response and buckling loads for composite shell structures. The analysis results also show that these nontraditional imperfections can be very important in some cases since they can significantly affect the buckling load. The nonlinear analysis results are also compared with the results from a traditional linear bifurcation buckling analysis. The results of this comparison suggest that the nonlinear analysis procedure can be used for determining accurate, high-fidelity design knockdown factors for predicting shell buckling and collapse in the design process. This high-fidelity nonlinear analysis procedure can be used to form the basis for a shell analysis and design approach that addresses some of the critical shell-buckling design criteria and design considerations for composite shell structures.

\section{References}

1. Anon., Buckling of Thin-Walled Circular Cylinders. NASA Space Vehicle Design Criteria, NASA SP-8007, September 1965.

2. Koiter, W. T., "On the Stability of Elastic Equilibrium," (in Dutch), H. J. Paris, Amsterdam, Holland, 1945; translation available as AFFDLTR-70-25, February 1970, Wright-Patterson Air Force Base.

3. von Kármán, T. and Tsien, H-S., "The Buckling of Thin Cylindrical Shells Under Axial Compression," Journal of the Aeronautical Science, Vol. 8, No. 8, June 1941, pp. 303-312.

4. Budiansky, B. and Hutchinson, J., "Dynamic Buckling of Imperfection Sensitive Structures," Proceedings of the 11 th IUTAM Congress, $\mathrm{H}$. Gortler, Ed., Springer-Verlag, Berlin, 1964, pp 636-651.

5. Árbocz, J. and Babcock, C. D., "The Effect of General Imperfections on the Buckling of Cylindrical Shells," Journal of Applied Mechanics, Vol. 36, Series E, No. 1, 1969, pp. 28-38.

6. Sechler, E. E., "The Historical Development of Shell Research and Design," in Thin-Shell Structures, Theory, Experiments and Design, Fung,
Y. C. and Sechler, E. E., Eds., Prentice-Hall, Englewood Cliffs, NJ, 1974, pp. 3-25.

7. Árbocz, J., "The Effects of Imperfect Boundary Conditions on the Collapse Behavior of Anisotropic Shells," Proceedings of the Joint Applied Mechanics and Materials ASME Summer Conference, AMD-MD'95, Los Angeles, CA, June 28-30, 1995.

8. Árbocz, J., Starnes, J. H., Jr., and Nemeth, M. P., "A Hierarchical Approach to Buckling Load Calculations," Proceedings of the 40th AIAA/ASME/ASCE/AHS/ASC Structures, Structural Dynamics and Materials Conference, St. Louis, MO, 1999. AIAA Paper No. 99-1232.

9. Koiter, W. T., Elishakoff, I., Li, Y. W., and Starnes, J. H., Jr., "Buckling of an Axially Compressed Imperfect Cylindrical Shell of Variable Thickness," Proceedings of the 35th AIAA/ASME/ASCE/AHS/ASC Structures, Structural Dynamics and Materials Conference, Hilton Head, SC, 1994. AIAA Paper No. 94-1339.

10. Holst, J. M., Rotter, J. M., and Calladine, C. R., "Imperfections in Cylindrical Shells Resulting from Fabrication Misfits," Journal of Engineering Mechanics, Vol. 125, No. 4, 1999, pp. 410-418.

11. Hilburger, M. W., Waas. A. M., and Starnes, J. H., Jr., "Response of Composite Shells with Cutouts to Internal Pressure and Compression Loads," AIAA Journal, Vol. 37, No. 2, 1998, pp.232-237.

12. Starnes, J. H., Jr., Hilburger, M. W., and Nemeth, M. P., "The Effects of Initial Imperfections on the Buckling of Composite Shells," to appear in Composite Structures: Theory and Practice, ASTM STP 1383.

13. Rankin, C. C., Brogan, F. A., Loden, W. A., and Cabiness, H. D., "STAGS Users Manual, Version 3.0," Lockheed Martin Missiles \& Space Co., Inc., Advanced Technology Center, Report LMSC P032594, 1999.

14. Riks, E., "Progress in Collapse Analysis," Journal of Pressure Vessel Technology, Vol. 109, 1987, pp. 27-41.

15. Park, K. C., "An Improved Stiffly Stable Method for Direct Integration of Nonlinear Structural Dynamics," Journal of Applied Mechanics, Vol. 42, June 1975, pp. 464-470.

16. Riks, E., Rankin, C. C., and Brogan, F. A., "On the Solution of Mode Jumping Phenomena in Thinwalled Shell Structures," Computer Methods in Applied Mechanics and Engineering, Vol. 136(12). 1996, pp. 59-92. 

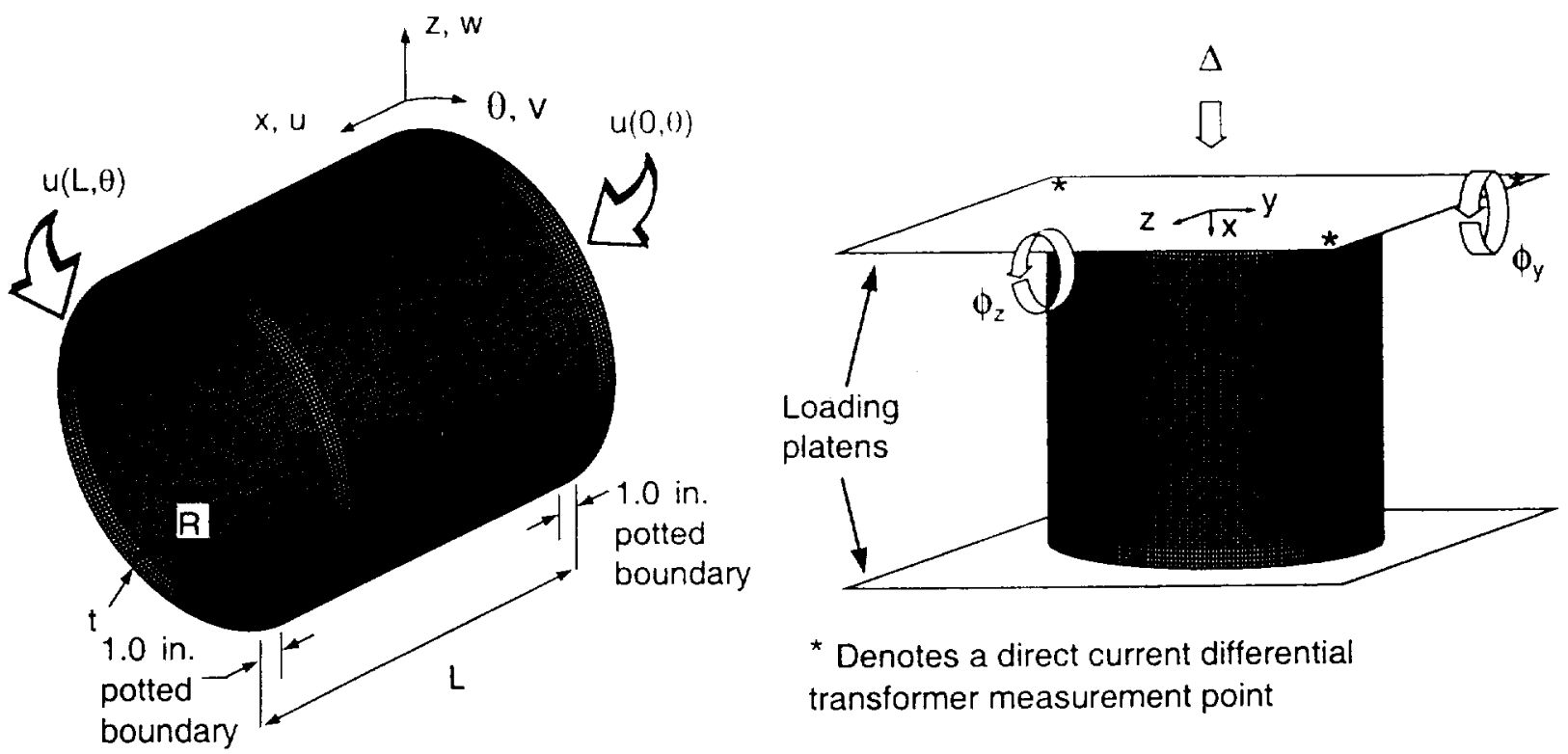

Fig. 1 Typical finite-element model geometry and boundary conditions.

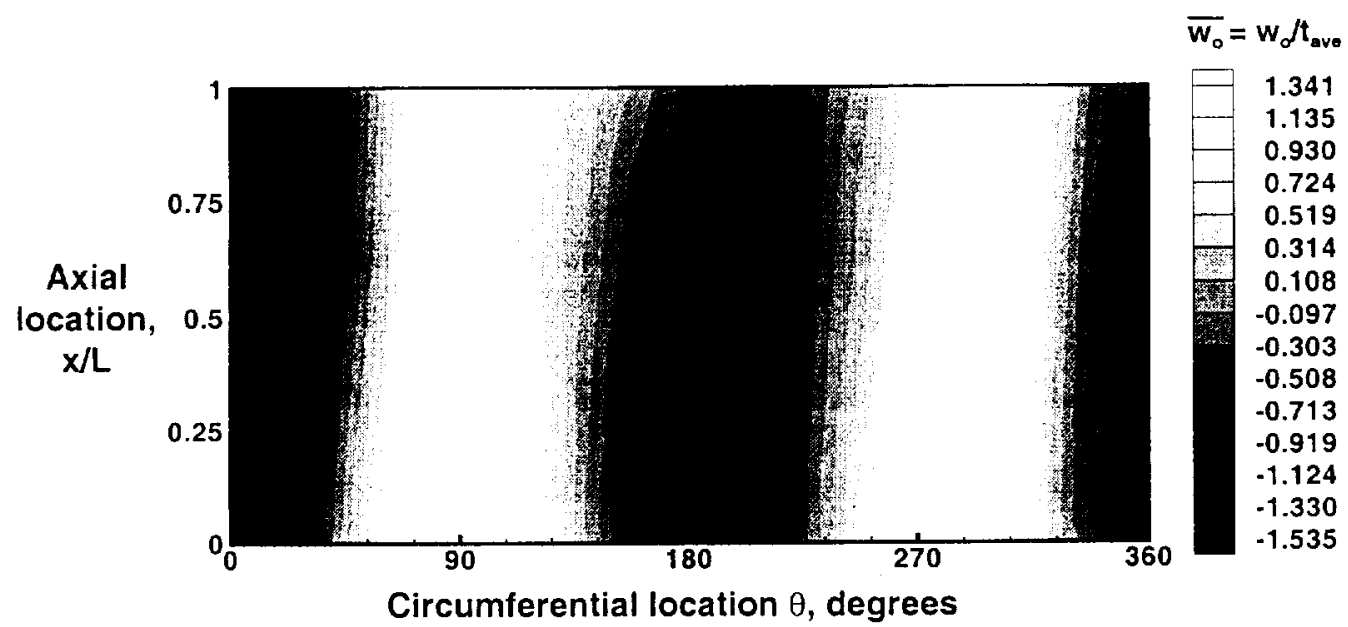

Fig. 2 Measured inner-surface imperfection shape for the cylinder specimen.

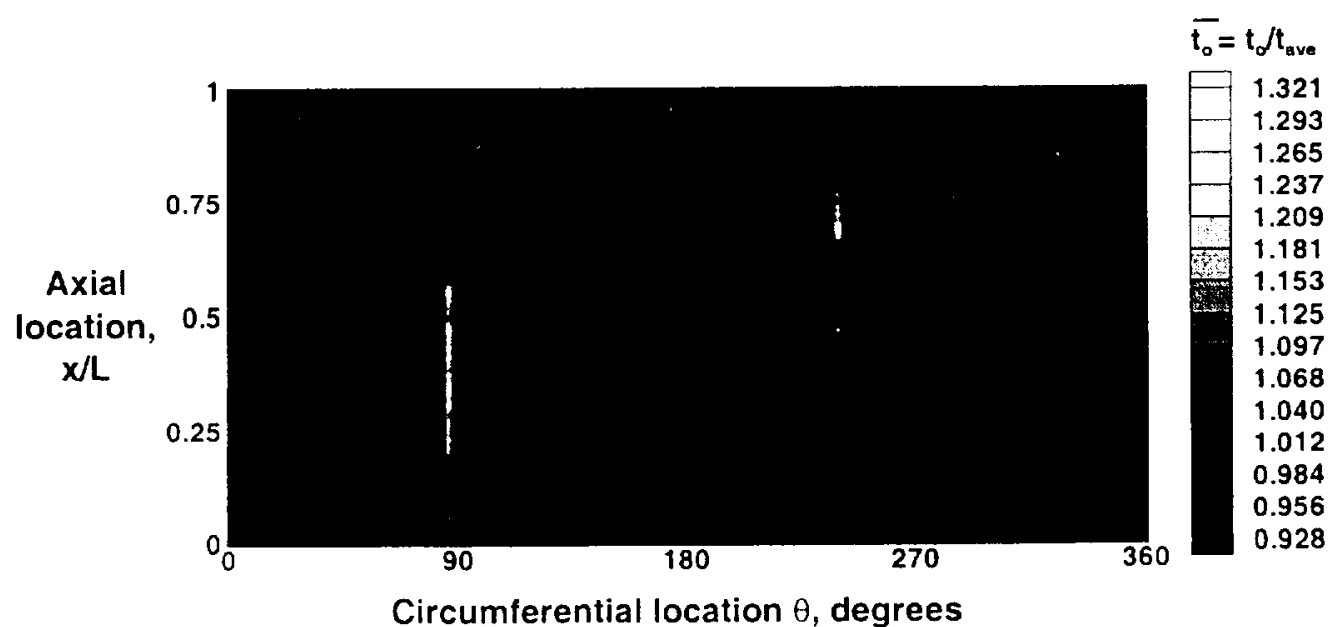

Fig. 3 Measured wall thickness variation for the cylinder specimen. 


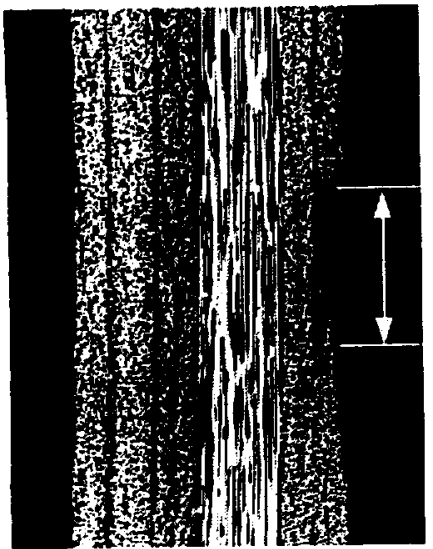

a) Ply-gap in a $45^{\circ}$ outersurface lamina ply

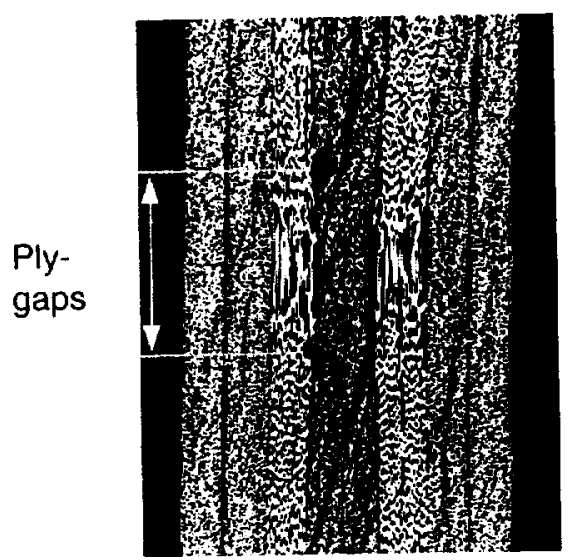

b) Ply-gap in a $90^{\circ}$ midsurface lamina ply

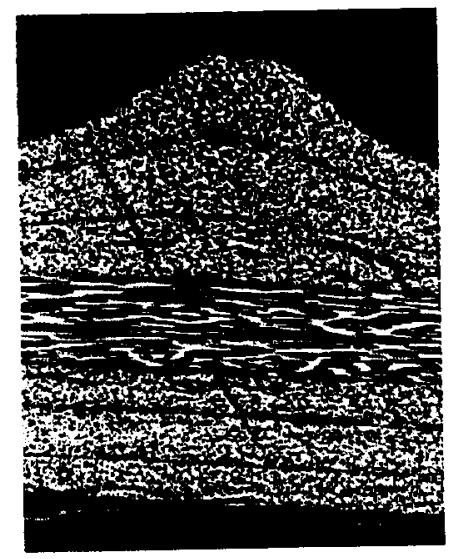

c) outer-surface ridge

Fig. 4 Magnified cross-sectional views of lamina ply-gaps and a magnified cross-sectional view of an outersurface ridge.

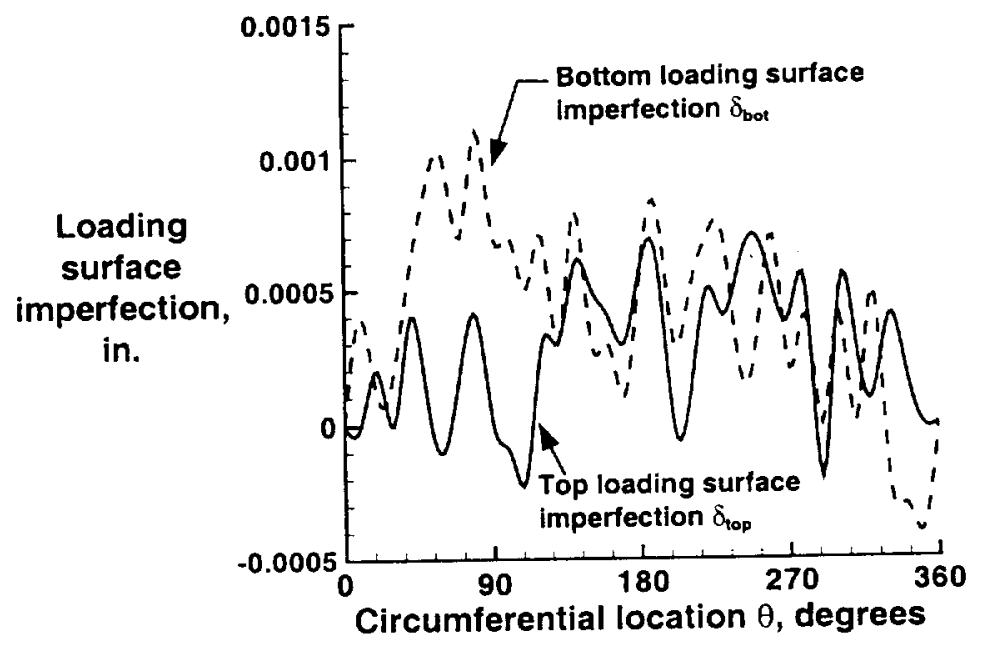

Fig. 5 Measured shell-end or loading-surface imperfections for the cylinder specimen.

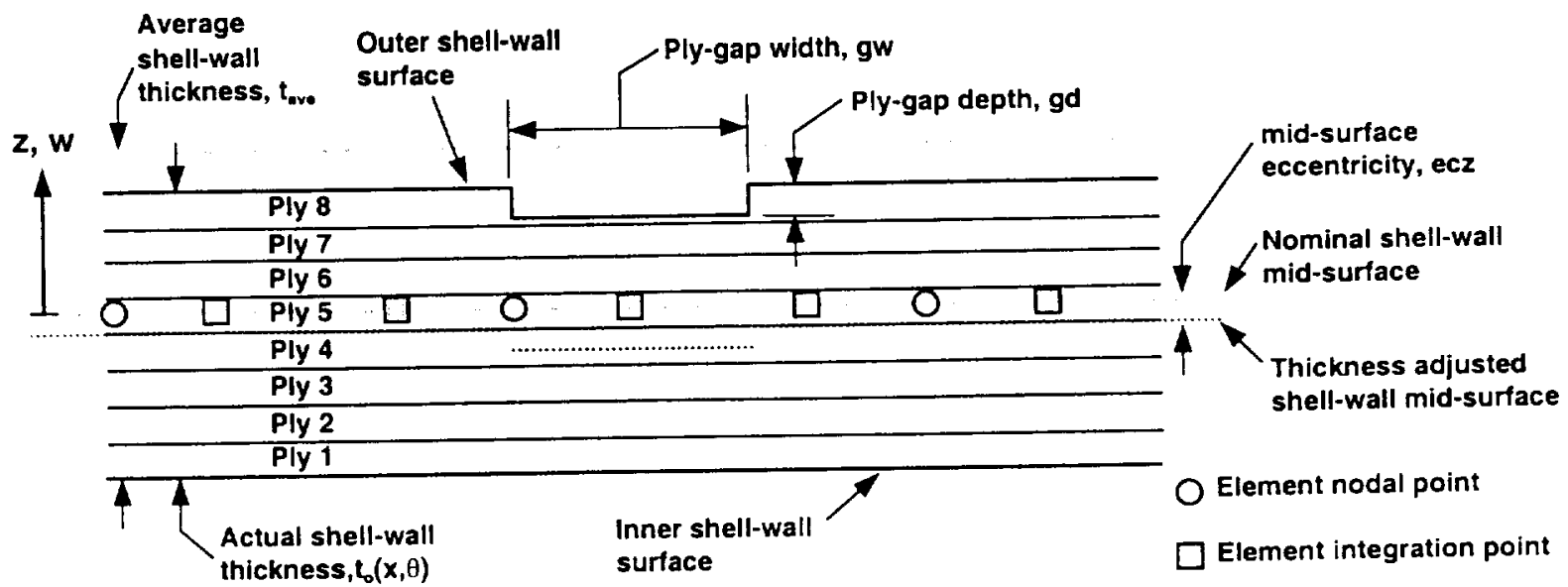

Fig. 6 Typical laminate model geometry including a lamina ply-gap. 


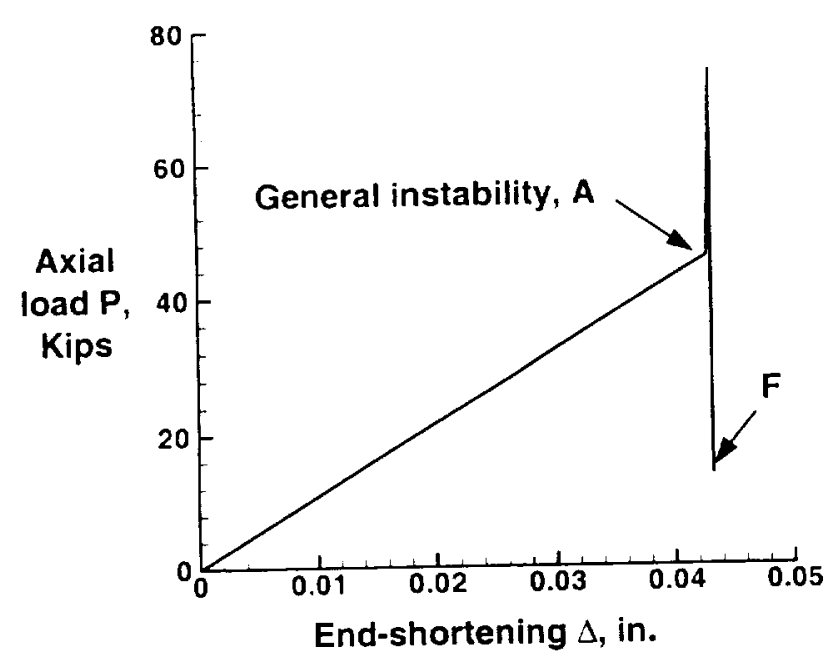

a) Load-shortening response

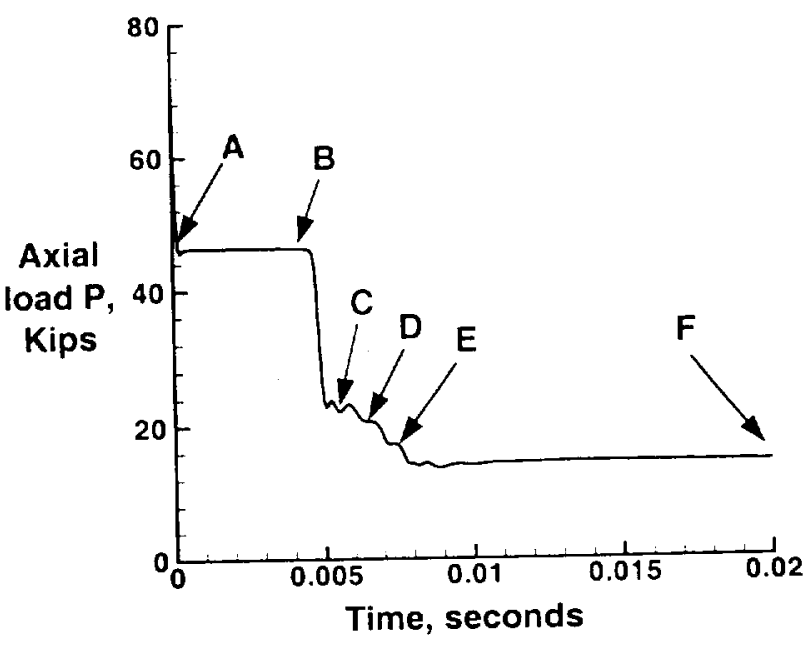

b) Load-time history during collapse

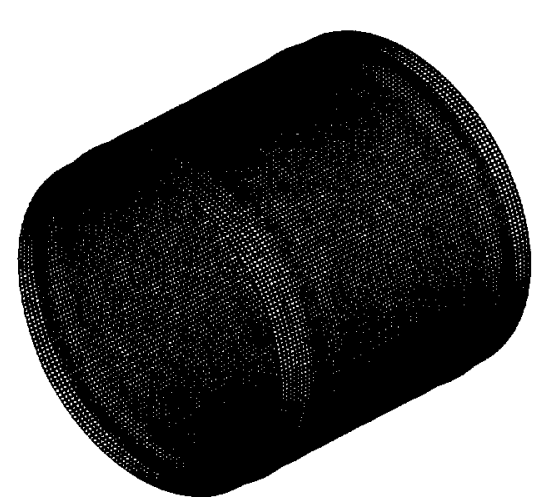

c) Deformation Pattern A Time $=0.0$ seconds $\mathrm{P}=45.9$ Kips

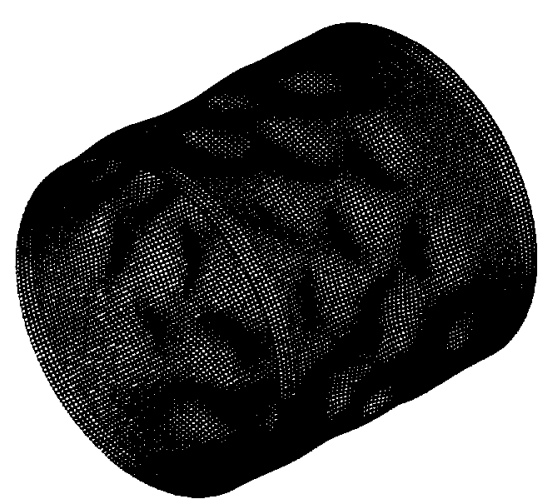

f) Deformation Pattern $D$ Time $=0.00639$ seconds $\mathrm{P}=20.68 \mathrm{Kips}$

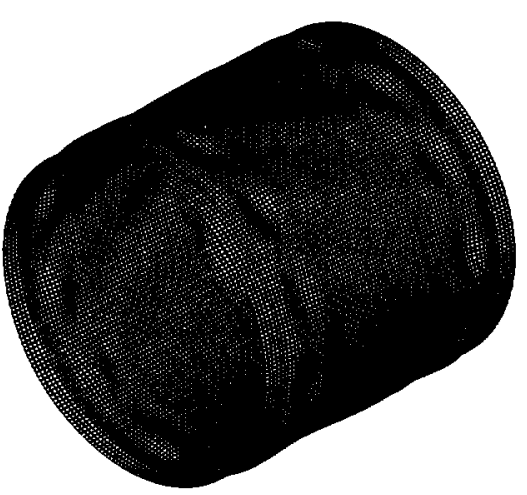

d) Deformation Pattern B Time $=0.00458$ seconds $\mathrm{P}=46.1 \mathrm{Kips}$

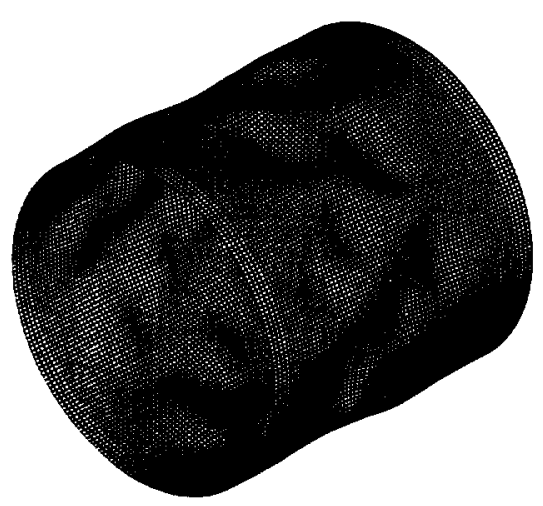

g) Deformation Pattern $E$ Time $=0.0072 !$ seconds $\mathrm{P}=17.20 \mathrm{Kips}$

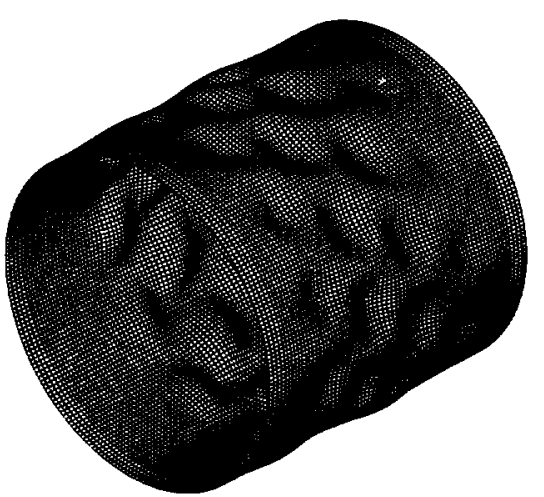

e) Deformation Pattern C Time $=0.00557$ seconds $\mathrm{P}=22.12 \mathrm{Kips}$

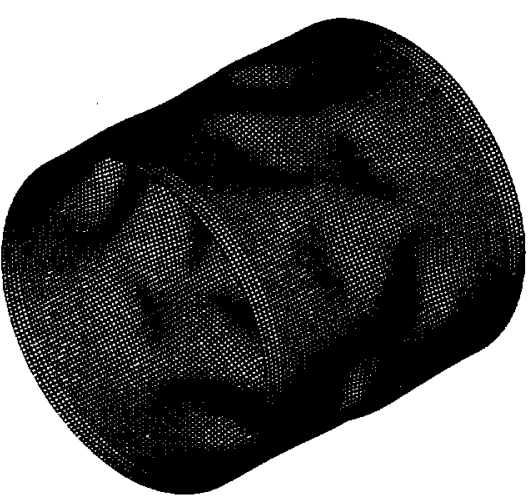

h) Deformation Pattern F Time $=0.02$ seconds $\mathrm{P}=14.32 \mathrm{Kips}$

Fig. 7 Nonlinear response of a geometrically perfect compression-loaded quasi-isotropic cylindrical shell. 


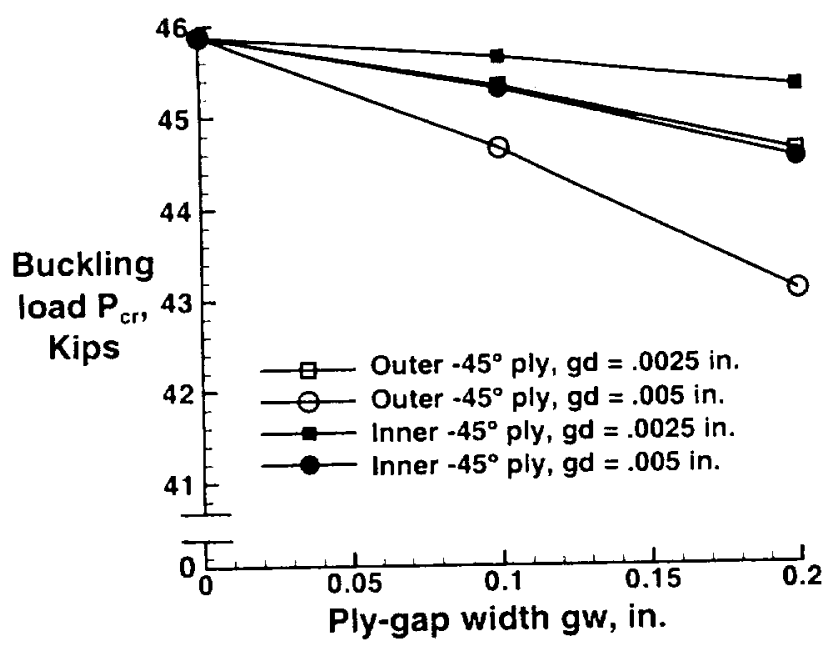

a) Ply-gaps in the outer $-45^{\circ}$ lamina ply (ply 8 ) and the inner $-45^{\circ}$ lamina ply (ply 1 ).

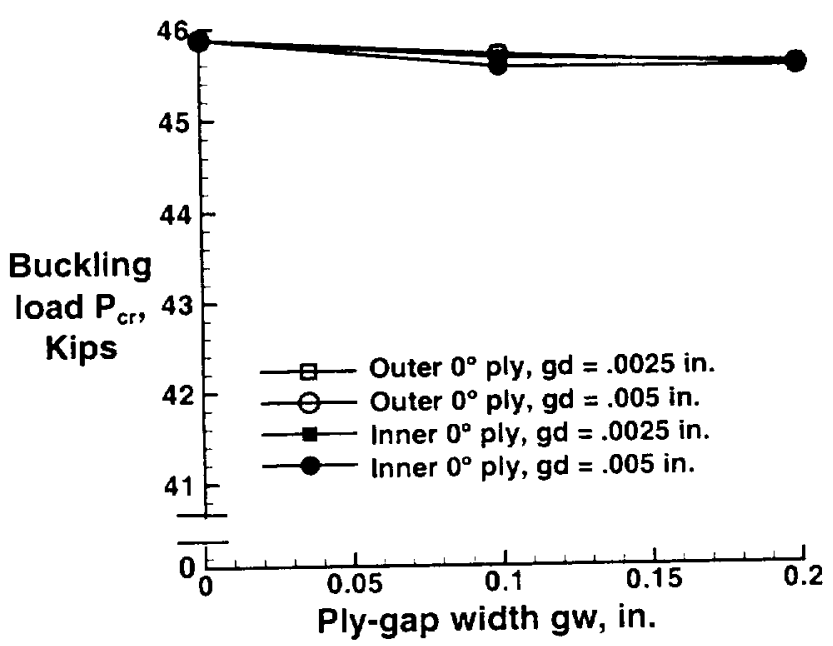

c) Ply-gaps in the outer $0^{\circ}$ lamina ply (ply 6) and the inner $0^{\circ}$ lamina ply (ply 3 ).

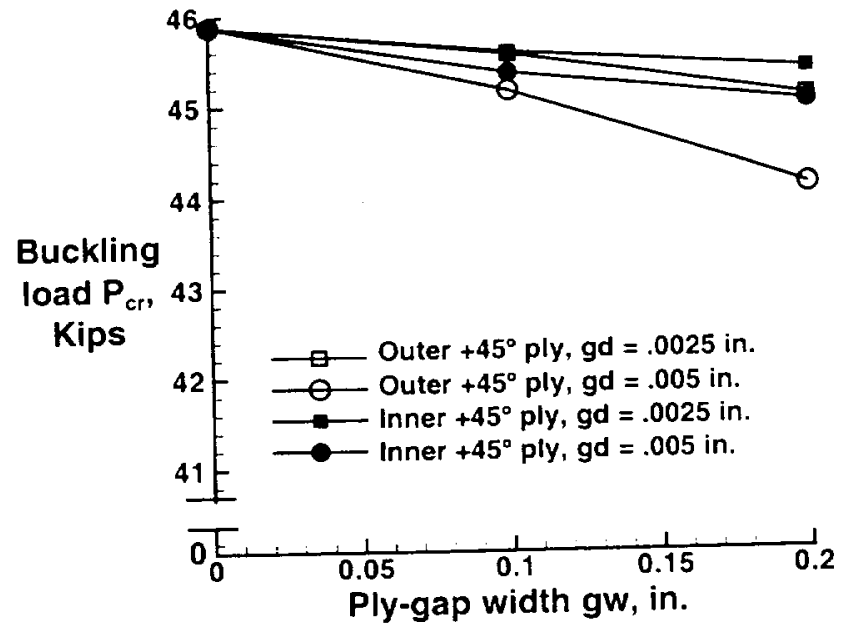

b) Ply-gaps in the outer $+45^{\circ}$ lamina ply (ply 7) and the inner $+45^{\circ}$ lamina ply (ply 2 ).

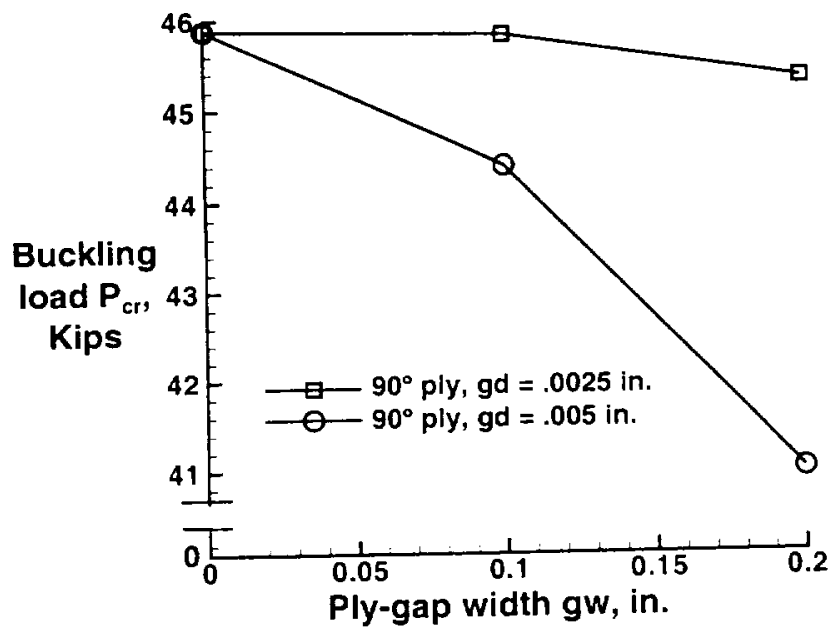

d) Ply-gaps in the $90^{\circ}$ lamina plies (ply 4 or ply 5 ).

Fig. 8 Effects of lamina gap-width (gw), gap-depth (gd), gap orientation, and gap location within the laminate on the buckling load of a compression-loaded quasi-isotropic cylinder.

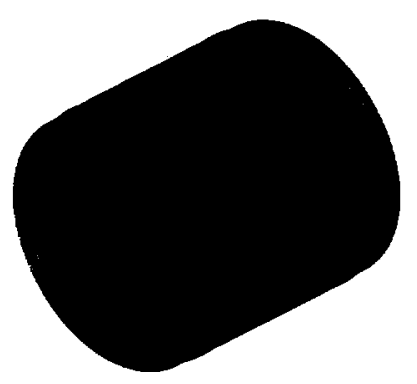

a) Time $=0.0$ seconds $P=41.71$ Kips

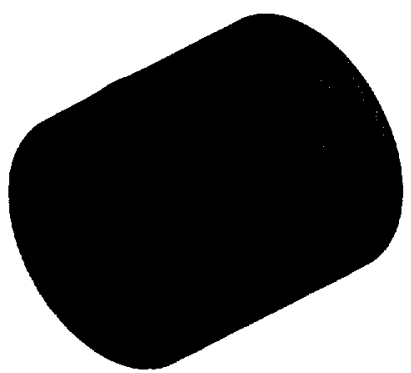

b) Time $=0.00123$ seconds $\mathrm{P}=33.45 \mathrm{Kips}$

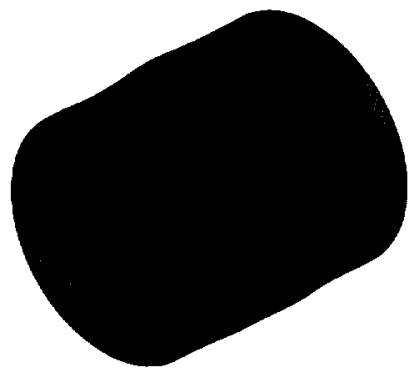

c) Time $=0.00291$ seconds $\mathrm{P}=17.34 \mathrm{Kips}$

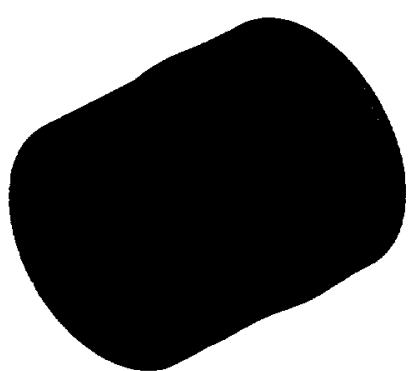

d) Time $=0.0271$ seconds $P=13.29 \mathrm{Kips}$

Fig. 9 Transient collapse response of a compression-loaded quasi-isotropic cylinder with a $-45^{\circ}$ helical plygap, $\mathrm{gw}=0.2 \mathrm{in} ., \mathrm{gd}=0.005 \mathrm{in}$. 


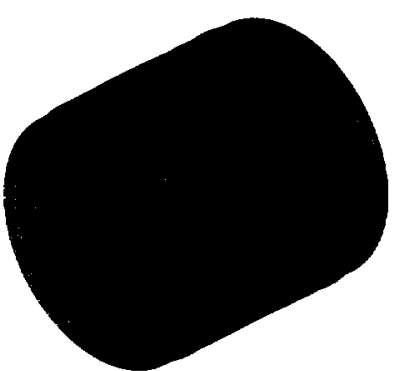

a) Time $=0.0$ seconds $\mathrm{P}=45.74 \mathrm{Kips}$

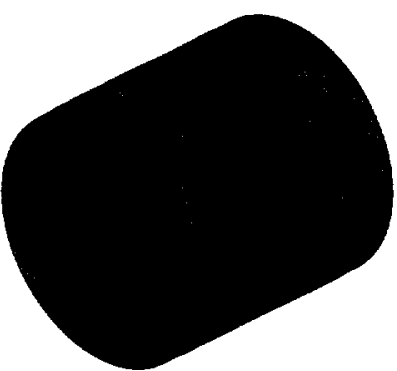

b) Time $=0.00159$ seconds $\mathrm{P}=43.4 \mathrm{Kips}$

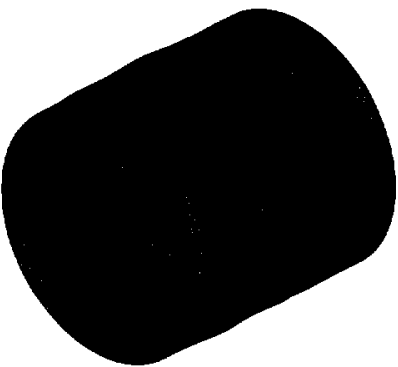

c) Time $=0.00323$ seconds $\mathrm{P}=17.57 \mathrm{Kips}$

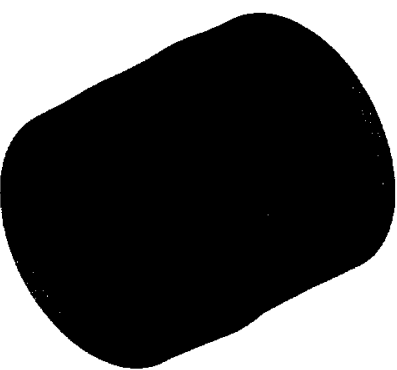

d) Time $=0.0271$ seconds $P=14.28$ Kips

Fig. 10 Transient collapse response of a compression-loaded quasi-isotropic cylinder with a $0^{\circ}$ axially aligned ply-gap, gw $=0.2$ in., $\mathrm{gd}=0.005 \mathrm{in}$.

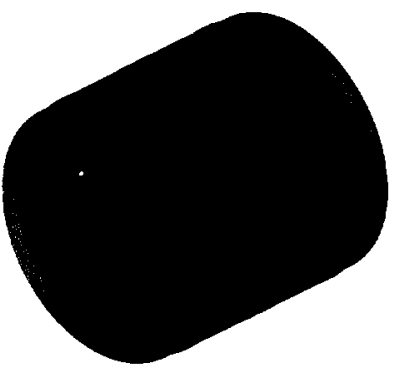

a) Time $=0.0$ seconds $\mathrm{P}=41.44$ Kips

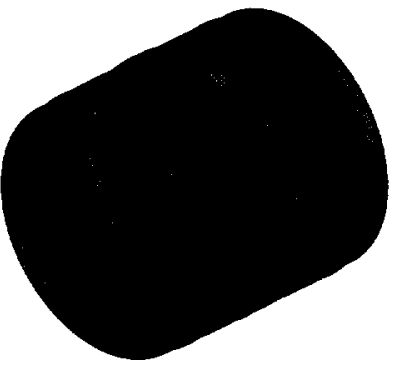

b) Time $=0.00363$ seconds
$P=41.90$ Kips

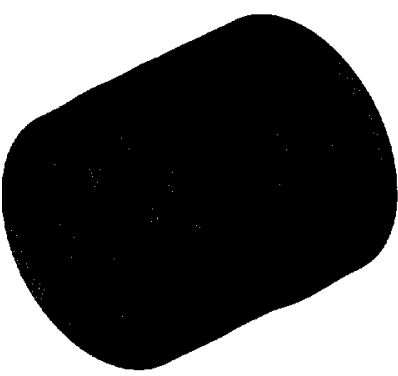

c) Time $=0.00608$ seconds $\mathrm{P}=20.0 \mathrm{Kips}$

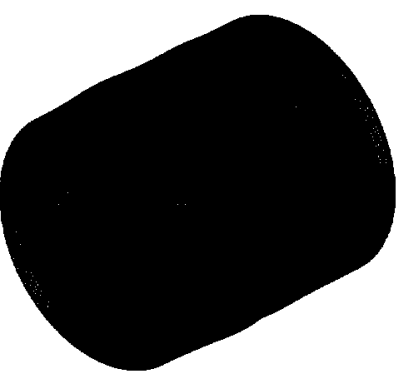

d) Time $=0.0299$ seconds $\mathrm{P}=13.24 \mathrm{Kips}$

Fig. 11 Transient collapse response of a compression-loaded quasi-isotropic cylinder with a $90^{\circ}$ circumferentially aligned ply-gap, $\mathrm{gw}=0.2 \mathrm{in}$., $\mathrm{gd}=0.005 \mathrm{in}$.

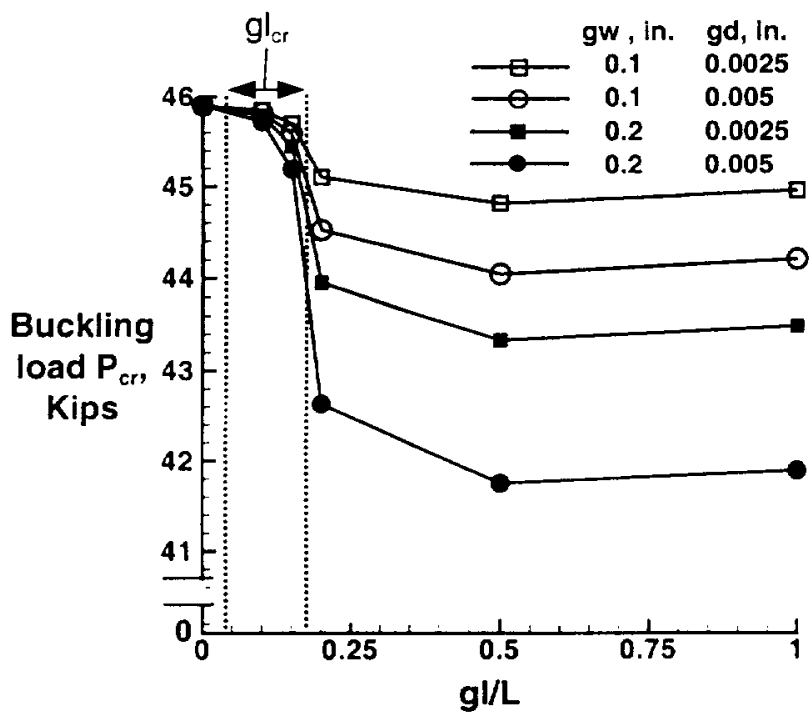

a) $-45^{\prime \prime}$ helical ply-gap

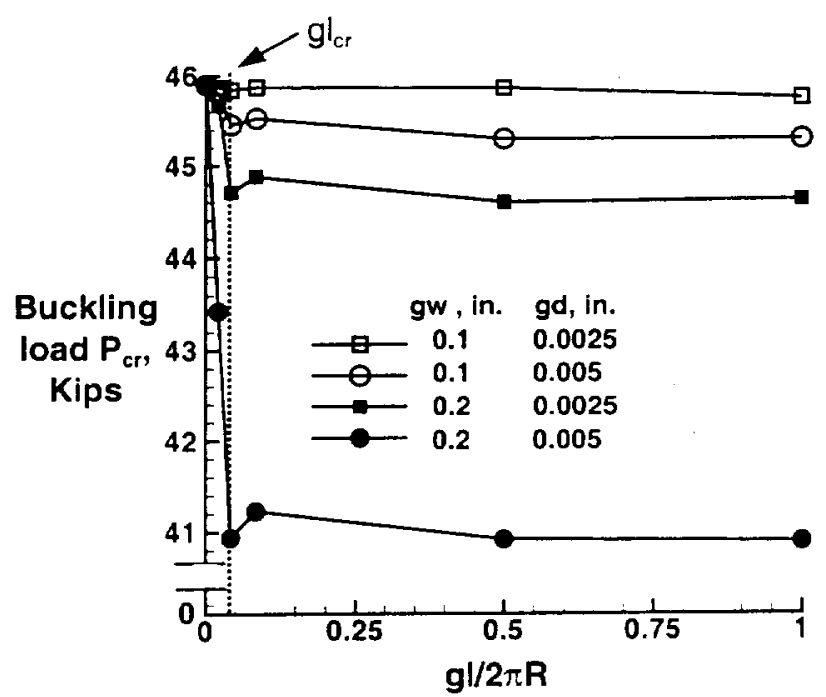

b) $90^{\circ}$ circumferential ply-gap

Fig. 12 Effects of ply-gap length (gl) on the buckling load of a compression-loaded quasi-isotropic cylinder. 


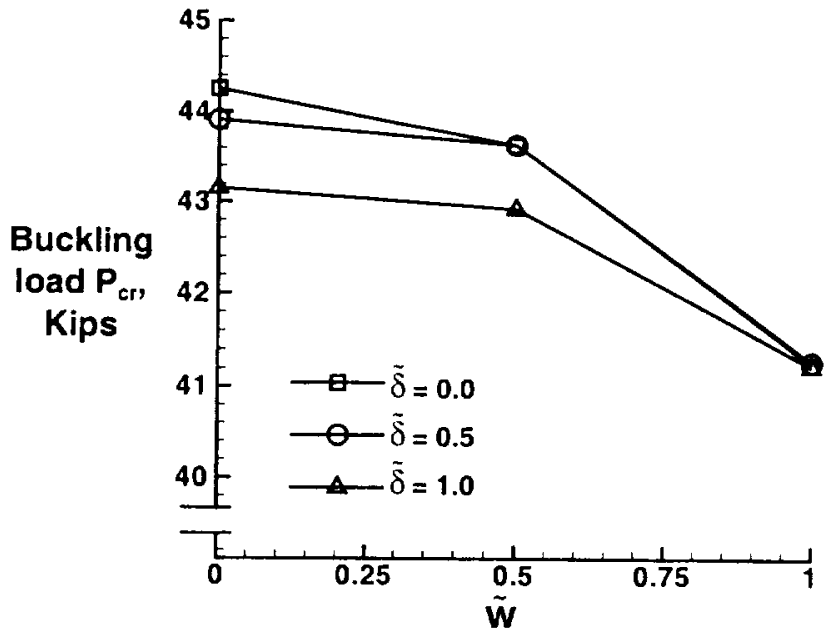

a) $\tilde{\mathrm{t}}=0.0$

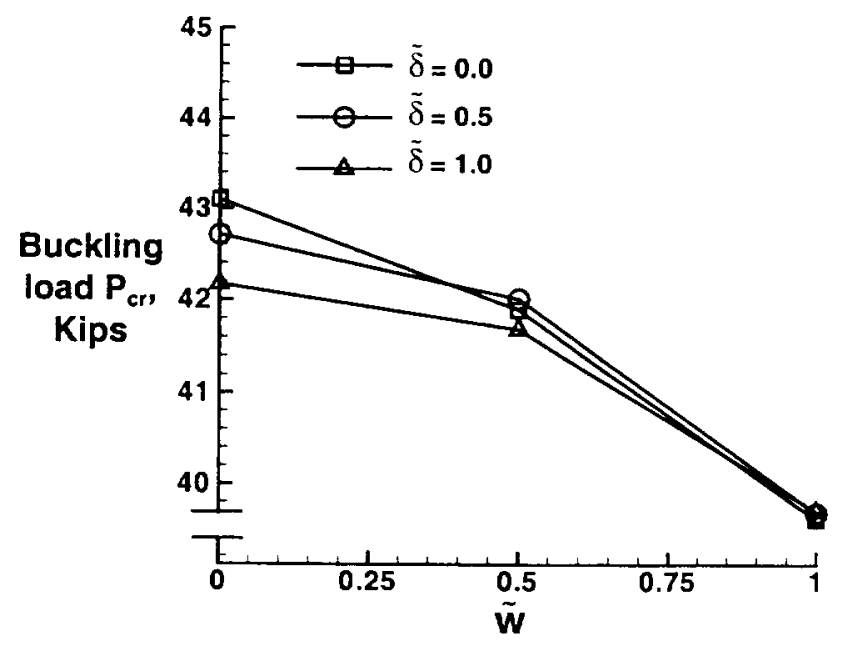

b) $\tilde{t}=1.0$

Fig. 13 Effects of initial imperfections on the buckling load of a compression-loaded quasi-isotropic cylindrical shell.

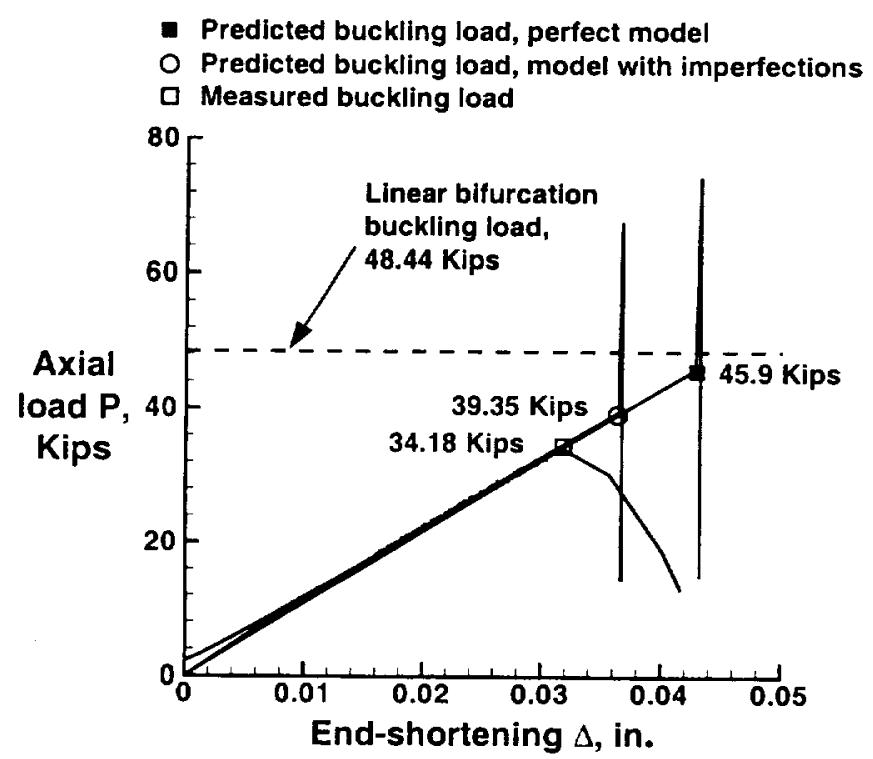

Fig. 14 Numerically predicted and experimentally measured load-end-shortening response curves for a compression-loaded quasi-isotropic cylindrical shell. 